\title{
Épocas de plantio e doses de zinco em alface tipo americana
}

\author{
Geraldo M de Resende'; Jony E Yuri²; Rovilson J de Souza ${ }^{3}$ \\ ${ }^{2}$ Embrapa Semi-Árido, C. Postal 23, 56302-970 Petrolina-PE; ${ }^{2}$ UNINCOR, Av. Castelo Branco, 82; Chácara das Rosas, $37410-000$ Três \\ Corações-MG; ${ }^{3}$ UFLA-Dep ${ }^{\text {to }}$ Agricultura, C. Postal 37, 37200-000 Lavras-MG; gmilanez@ cpatsa.embrapa.br
}

\section{RESUMO}

Com o objetivo de avaliar a influência de épocas de plantio e doses de zinco sobre o rendimento da alface tipo americana (Lactuca sativa L.), realizou-se um experimento no município de Três Pontas-MG, sob delineamento de blocos ao acaso, em parcelas subdivididas, com quatro repetições. As parcelas foram constituídas pelas épocas de plantio (outono e inverno) e as subparcelas pelas doses de zinco $(0,00 ; 0,18 ; 0,36 ; 0,54 \mathrm{e} 0,72 \mathrm{~kg} / \mathrm{ha})$, sendo utilizada a cultivar Raider. A maior massa fresca total, comercial e circunferência da cabeça foram observadas no plantio de inverno e o maior comprimento do caule pelo plantio de outono. Os maiores rendimentos de massa fresca total e comercial e máxima circunferência da cabeça foram obtidos com as doses 0,$45 ; 0,49$ e $0,44 \mathrm{~kg} / \mathrm{ha}$ de zinco. $\mathrm{O}$ comprimento do caule não foi influenciado pelas doses de zinco.

Palavras-chave: Lactuca sativa, massa fresca total e comercial, micronutrientes.

\section{ABSTRACT \\ Influence of planting times and zinc doses on crisphead lettuce}

An experiment was carried out in Três Pontas County, Minas Gerais State, Brazil to evaluate the influence of planting times and zinc doses on yield of crisphead lettuce (Lactuca sativa L.), cv. Raider. The trial was a split-plot arranged as randomized complete block design with four replications. The main plots (winter and autumn season) constituted the growing season and, the zinc doses $(0.0 ; 0.18 ; 0.36$; 0.54 and $0.72 \mathrm{~kg} / \mathrm{ha}$ ) were the subplot factors. The highest values of total and commercial fresh mass and, head circumference were obtained in the winter season and, of stem length in the autumn season. The highest yields of total and commercial fresh mass and, of maximum head circumference were verified using zinc doses of $0.45 ; 0.49$ and $0.44 \mathrm{~kg} / \mathrm{ha}$. The zinc doses did not influence the stem length.

Keywords: Lactuca sativa, fresh mass, total and commercial yield, micronutrient.

(Aceito para publicação em 11 de abril de 2007; aceito em 8 de setembro de 2008) (Received in April 11, 2007; accepted in September 8, 2008)

A alface americana vem adquirindo importância crescente no país. O plantio deste tipo de alface visa atender as redes fast food e, atualmente, tem-se constatado o aumento no consumo desta hortaliça também na forma de salada. É a hortaliça folhosa de maior valor comercial no Brasil (Santos et al. 2001).

A época de plantio é um fator fundamental no cultivo da alface tipo americana, por se tratar de uma planta bastante influenciada por condições ambientais uma vez que se adapta melhor às regiões de clima ameno (Moreira et al., 2001). Por outro lado, o cultivo em ambiente protegido por cobertura plástica tem viabilizado a produção de alface durante todo o ano nas regiões tropicais e subtropicais. A cobertura protege as plantas contra danos provocados por chuvas, ventos fortes e incidência direta da radiação solar e geada, em regiões de inverno muito frio (Castellane \& Araújo, 1995).

A temperatura é o fator ambiental que mais influencia na formação da cabeça pois está relacionada com o florescimento (Whitaker \& Ryder, 1974). De acordo com Sanders (1999), a alface americana se adaptada às condições de temperatura amena, tendo como ótima a faixa entre 15,5 e $18,3^{\circ} \mathrm{C}$. Entre 21,1 e $26,6^{\circ} \mathrm{C}$, a planta floresce e produz sementes. No entanto, pode tolerar alguns dias com temperaturas de 26,6 a $29,4^{\circ} \mathrm{C}$, desde que as temperaturas noturnas sejam baixas.

Outro fator que pode afetar o desenvolvimento da planta é o fotoperíodo, o qual, segundo Conti (1994), não é problema para o cultivo de verão no Brasil pois as cultivares européias importadas já estão adaptadas a dias mais longos do que os que ocorrem no país. A expansão da cultura está ocorrendo em áreas de latitudes menores, conseqüientemente, o fotoperíodo não é obstáculo. Entretanto, em regiões ou localidades de menores latitudes, normalmente há ocorrência de temperaturas mais altas. Nestas situações, há a necessidade de se escolher áreas de maiores altitudes, pois estas influenciam diretamente a temperatura local. Verifica-se que nas regiões serranas do Rio de Janeiro e no cinturão verde de São Paulo, em altitudes superiores a 800 m é possível cultivar a alface tipo americana ao longo do ano. Já em localidades com altitude inferior a $400 \mathrm{~m}$ (temperaturas altas), desde que se utilize cultivares adaptadas, pode-se cultivar a alface na maioria dos meses (Filgueira, 2000).

Em plantio de inverno, Bueno (1998) obteve para a cultivar Lorca, massa fresca total e comercial de 801,2 e 461,2 g/planta, respectivamente; enquanto Mota (1999) obteve 1000,0 e 695,0 g/planta, respectivamente. Já Alvarenga (1999), usando a cultivar Raider, obteve massa fresca total e comercial de 1011,0 e 676,8 g/planta, respectivamente. Por outro lado, Yuri et al. (2002) obtiveram maiores produtividades de massa fresca total, comercial e circunferência da cabeça com o uso de várias cultivares em plantio de outono em comparação com o cultivo de verão. Também no outono, Yuri et al. (2005) encontraram resultados semelhantes.

O processo produtivo brasileiro passa por uma fase em que a produtividade, a eficiência, a lucratividade e a sustentabilidade são aspectos que requerem maior atenção. Neste contexto, os micronutrientes, cuja importância é conhecida há várias décadas, apenas re- 
centemente passaram a ser utilizados de modo rotineiro nas adubações. Em especial tem-se o zinco, cuja importância é indiscutível em razão das freqüentes situações de deficiência em culturas em geral (Abreu et al., 2001).

Os solos brasileiros, de maneira geral, são pobres em zinco devido ao material de origem, uma vez que este elemento nutriente tem como fonte primária os minerais ferro-magnesianos (Chesworth, 1991), que estão relacionados com rochas básicas, e a maioria dos solos do Brasil, são formados a partir de rochas ácidas e, ou, sedimentares. A produção em áreas de cerrado, normalmente pobres em micronutrientes, principalmente zinco e boro, torna a prática da adubação com esses nutrientes de grande importância para a cultura. Segundo Moreira et al. (2001), em alface, na ausência de $\mathrm{Zn}$, as raízes permaneceram escuras, e as folhas apresentavam textura coriacéa com necrose nos bordos, menor área foliar, e menor número de folhas. Os sintomas de carência de zinco ocorrem, especialmente em baixadas esgotadas pelo cultivo intensivo, podendo ser corrigidos pela adubação foliar (Filgueira, 2000).

$\mathrm{O}$ efeito positivo do fornecimento de zinco solução nutritiva em alface é relatado por Moreira et al. (2001) que observaram com relação à matéria seca da planta inteira, no nível baixo de $\mathrm{P}$, não haver efeito da adição de Zn na solução nutritiva; sendo que no nível normal de $\mathrm{P}$, a adição de $\mathrm{Zn}$ proporcionou maior produção de matéria seca, e no nível alto de $\mathrm{P}$, as doses normal e alta de Zn proporcionaram maiores incrementos na produção de matéria seca. Fontes et al. (1982) em estudo conduzido por dois anos, observaram que na ausência do $\mathrm{Zn}$ ocorreram decréscimos médios 25,5; 31,1 e 17,4\%, respectivamente, na produção total e comercial e na massa fresca da cabeça de alface. Por outro lado, Iorio et al. (1996), não encontraram efeitos do $\mathrm{Zn}$ e do $\mathrm{P}$ sobre área foliar e a produção de matéria seca da parte aérea e da raiz de alface, em meio hidropônico.

As informações relativas à aplicação de zinco na produção de alface, ainda são restritas e não conclusivas. Por essa razão, os produtores realizam pulveri- zações foliares semanais com produtos contendo zinco, sem a garantia de que este procedimento seja adequado, gerando preocupação quanto à sua eficiência e aproveitamento pela cultura.

Em razão do exposto, realizou-se um trabalho com o objetivo de avaliar diferentes épocas de plantio e doses de zinco via foliar no cultivo de alface tipo americana, nas condições do Sul de Minas Gerais.

\section{MATERIAL E MÉTODOS}

O experimento foi realizado no município de Três Pontas, Sul de Minas Gerais, a uma altitude de $870 \mathrm{~m}$, situada a $21^{\circ} 22^{\prime} 00^{\prime}$ ' de longitude sul e $45^{\circ} 30^{\prime} 45^{\prime}$ ' de longitude oeste (IBGE, 2004). O solo da área experimental foi classificado como Latossolo Vermelho Distroférrico, textura argilosa (EMBRAPA, 1999), apresentando as características químicas: $\mathrm{K}: 99,2 \mathrm{mg} \mathrm{dm}^{-3}$; P: 44,0 $\mathrm{mg} \mathrm{dm}^{-3}$; $\mathrm{Ca}: 4,3 \mathrm{cmol}_{\mathrm{c}} \mathrm{dm}^{-3} ; \mathrm{Mg}$ : $0,8 \mathrm{cmol}_{\mathrm{c}} \mathrm{dm}^{-3} ; \mathrm{Al}: 0,0 \mathrm{cmol}_{\mathrm{c}} \mathrm{dm}^{-3} ; \mathrm{H}+$ Al: 2,0 $\mathrm{cmol}_{\mathrm{c}} \mathrm{dm}^{-3} ; \mathrm{Zn}: 1,1 \mathrm{mg} \mathrm{dm}^{-3}$; Fe: 29,9 $\mathrm{mg} \mathrm{dm}^{-3}$; Mn: $12,2 \mathrm{mg} \mathrm{dm}^{-3}$; Cu: $1,0 \mathrm{mg} \mathrm{dm}^{-3}$; B: $0,6 \mathrm{mg} \mathrm{dm}^{-3} ; \mathrm{pH} \mathrm{em} \mathrm{H}_{2} \mathrm{O}$ (1:2,5): 5,8 e matéria orgânica: $21 \mathrm{~g} \mathrm{~kg}^{-1}$.

Utilizou-se o delineamento experimental de blocos ao acaso, com quatro repetições, em parcelas subdivididas, sendo as parcelas constituídas pelas épocas de plantio (outono, com semeadura em 04/02/02 e inverno com semeadura 08/04/02 ) e as subparcelas pelas cinco doses de zinco $(0,00 ; 0,18 ; 0,36 ; 0,54 \mathrm{e}$ $0,72 \mathrm{~kg} / \mathrm{ha})$, sendo utilizada a cultivar Raider. Como fonte de zinco utilizouse o sulfato de zinco ( $20 \%$ de $\mathrm{Zn}$ ) sendo a aplicação realizada via pulverização foliar aos 21 dias após o transplantio. Utilizou-se um pulverizador manual com 4 L de capacidade, em máxima pressão, calibrado para gastar $300 \mathrm{~L}$ de calda por hectare, não sendo usado qualquer tipo de adesivo.

As parcelas experimentais constituíram-se de canteiros com quatro linhas de 2,1 m de comprimento, com espaçamento entre linhas de $0,30 \mathrm{~m} \mathrm{e}$ entre plantas de $0,35 \mathrm{~m}$. As linhas centrais formaram a área útil, desprezando-se as duas plantas de cada extremidade. Os canteiros em número de dois foram cobertos por estruturas de pro- teção (túnel alto com 2,0 m de altura, constituído por tubos de ferro galvanizados, cobertos com filme plástico transparente de baixa densidade, aditivado com anti-UV, de 100 micrômetros de espessura) e revestidos com filme plástico preto "mulching", de $4 \mathrm{~m}$ de largura e 35 micrômetros de espessura.

$\mathrm{Na}$ adubação de plantio utilizou-se $68 \mathrm{~kg} / \mathrm{ha}$ de $\mathrm{N}, 418 \mathrm{~kg} / \mathrm{ha}$ de $\mathrm{P}_{2} \mathrm{O}_{5}$ e 136 $\mathrm{kg} /$ ha de $\mathrm{K}_{2} \mathrm{O}$, incorporados ao solo com enxada rotativa na camada de $0,0-0,20$ m. As adubações de cobertura foram realizadas por meio de fertirrigações diárias durante todo o ciclo da cultura, totalizando $40 \mathrm{~kg} / \mathrm{ha}$ de $\mathrm{N}$ e $85 \mathrm{~kg} / \mathrm{ha}$ de $\mathrm{K}_{2} \mathrm{O}$, utilizando como fontes uréia e cloreto de potássio.

O transplante das mudas, formadas em bandejas multicelulares de 288 células cada uma, preenchidas com substrato artificial (Plantmax), foi realizado após 30 dias da semeadura. As irrigações foram diárias e os demais tratos culturais foram os comuns à cultura.

A colheita foi realizada aos 74 dias após a semeadura no outono e aos 92 dias no inverno, sendo avaliadas a massa fresca total e comercial (g/planta); circunferência da cabeça comercial $(\mathrm{cm})$ e comprimento do caule $(\mathrm{cm})$. Os dados foram submetidos à análise de variância, e quando necessário, as médias foram comparadas pelo teste Tukey a 5\%, ou ajustados a equações de regressão polinomial.

\section{RESULTADOS E DISCUSSÃO}

Houve efeitos significativos independentes para a época de plantio e doses de zinco para todas as características avaliadas, à exceção do comprimento de caule, que não apresentou efeito para doses, não se observando efeitos da interação entre os fatores.

$\mathrm{O}$ rendimento de massa fresca total no cultivo de inverno (942,2 g/planta) foi significativamente superior ao de outono (748,8 g/planta) (Tabela 1). Mota (1999) e Alvarenga (1999) em cultivo de inverno obtiveram massa fresca total por planta pouco superior com 1000 e 1011 g/planta (cvs. Lorca e Raider, respectivamente). Já Yuri et al. (2004a) 
Tabela 1. Massa fresca total e comercial, circunferência da cabeça e comprimento do caule da alface tipo americana em função da época de plantio (total and commercial fresh mass, head circunference and stem lenght of crisphead lettuce, depending on the planting season). Três Pontas-MG, Embrapa Semi-Árido, 2002.

\begin{tabular}{lrrc}
\hline \multirow{2}{*}{ Características } & \multicolumn{3}{c}{ Épocas de plantio } \\
\cline { 2 - 4 } & Inverno & Outono & CV (\%) \\
\hline Massa fresca total (g/planta)** & $942,2 \mathrm{a}$ & $748,8 \mathrm{~b}$ & 4,1 \\
Massa fresca comercial (g/planta)** & $564,9 \mathrm{a}$ & $467,0 \mathrm{~b}$ & 4,5 \\
${\text { Circunferência da cabeça }(\mathrm{cm})^{* *}}_{\text {Comprimento do caule }(\mathrm{cm})^{*}}^{44,1 \mathrm{a}}$ & $39,2 \mathrm{~b}$ & 6,0 \\
\hline
\end{tabular}

${ }^{1}$ Médias seguidas pela mesma letra nas linhas, não diferem entre si, pelo teste de Tukey ao nível de 5\% de probabilidade (means followed by the same letter in the line did not differ from each other, Tukey, $5 \%$ ); **Significativo ao nível de $1 \%$ de probabilidade, pelo teste de F (**significant at the level of $1 \%$ probability, F test); *Significativo ao nível de $5 \%$ de probabilidade, pelo teste de $\mathrm{F}((*$ significant at the level of $5 \%$ probability, $\mathrm{F}$ test).

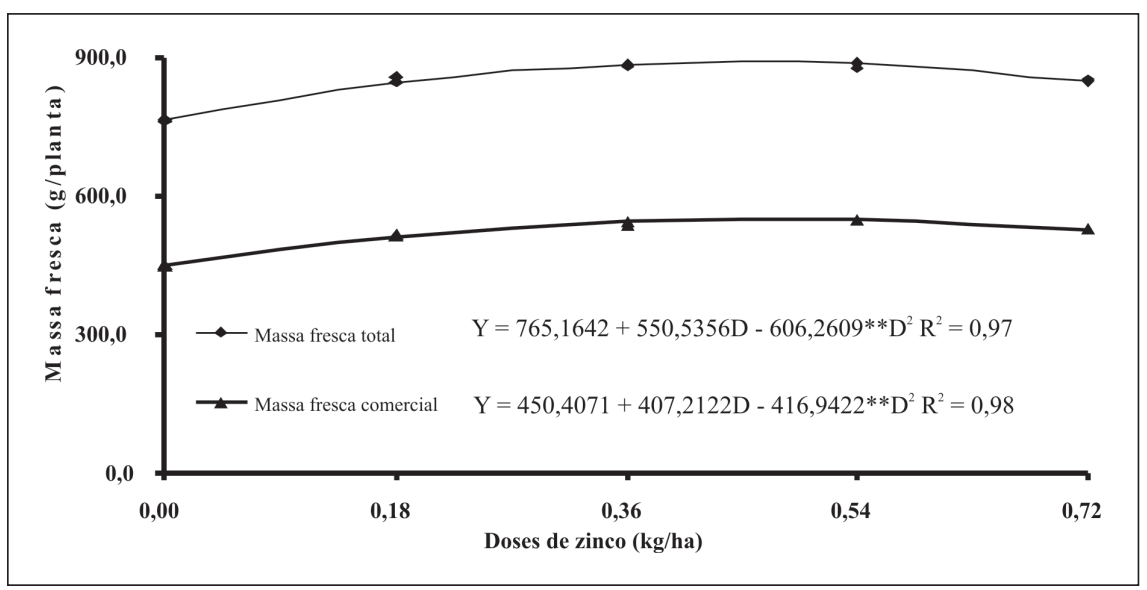

Figura 1. Massa fresca total e comercial de alface tipo americana em função de doses de zinco (total and commercial fresh mass of crisphead lettuce as a result of zinc doses). Três Pontas-MG, Embrapa Semi-Árido, 2002.

em condições de outono, obtiveram variações entre 594 a 1075 g/planta para diversas cultivares.

Para massa fresca comercial os resultados do cultivo de inverno (564,9 g/ planta) foram significativamente superiores aos de outono (467,0 g/planta) (Tabela 1). Estes resultados são inferiores aos obtidos por Alvarenga (1999) que encontrou em plantio de inverno uma massa comercial de $677 \mathrm{~g} /$ planta. Por outro lado, Yuri et al. (2004 a), em cultivo de outono, encontraram variações entre 427 a 739 g/planta entre diferentes cultivares avaliadas. Os melhores resultados obtidos no inverno podem ser explicados pela origem mediterrânea da alface, que se adapta melhor a condições de clima mais frio, já que nesta região as temperaturas médias variam de 10 a $20^{\circ} \mathrm{C}$ (Lindquivist, 1960; Cásseres, 1980). que obtiveram maior massa fresca comercial com a dose de $0,41 \mathrm{~kg} / \mathrm{ha}$ de zinco em condições de inverno, com a mesma cultivar. Fontes et al. (1982) observaram um decréscimo médio de 25,5 e $31,1 \%$, na produção total e comercial, em dois anos de estudo, na ausência da adubação com zinco em diferentes cultivares. Já Moreira et al. (2001) relataram efeito positivo da adição de zinco associado ao fósforo, na área foliar e na produção de massa seca da alface cultivada em solução nutritiva em casa de vegetação. O efeito significativo da aplicação de zinco, com conseqüente incremento na produtividade, deve-se provavelmente, à sua principal função como ativador enzimático, estando diretamente envolvido no metabolismo do nitrogênio (Faquin, 1997), sendo ainda importante para o crescimento (Grewal et al., 1997) e para manutenção da integridade da membrana plasmática da raiz (Welch \& Norvell, 1996).

Para comprimento do caule (Tabela 1) o cultivo de inverno $(3,7 \mathrm{~cm})$ foi significativamente inferior ao de outono $(5,7 \mathrm{~cm})$, sendo este efeito observado apenas para épocas. Yuri et al. (2004a) observaram variações no comprimento do caule de diferentes cultivares no outono oscilando entre 2,9 e 4,9 cm. Salienta-se que a melhor performance observada do cultivo no período de temperaturas mais baixas (inverno), nos meses de maio a julho, evidenciando menor comprimento do caule, é plenamente justificado pela melhor adaptação da cultura, pois, segundo Whitaker \& Ryder (1974), a temperatura é o fator ambiental que mais influencia na formação de cabeça, uma vez que está relacionada com o florescimento, que por sua vez acelera-se com maior temperatura. Resende et al. (2005a), salientam que há uma tendência da alface americana em condições de cultivo de verão (temperatura mais altas) apresentar maiores comprimentos de caule comparativamente ao cultivo de inverno onde esta se mostra perfeitamente adaptada. Neste contexto, mesmo em condições de temperaturas intermediárias (outono) este fato ficou evidenciado.

Não se observou efeito significativo para doses de zinco no comprimento 
do caule que variou de 4,5 a $4,8 \mathrm{~cm}$. Resultados corroborados por aqueles obtidos por Resende et al. (2005b) que também não verificaram efeito da aplicação de zinco no comprimento do caule. Menores comprimentos de caule são desejáveis para este tipo de alface (americana), principalmente quando destinada à indústria de beneficiamento (onde as cabeças são fatiadas e embaladas), minimizando as perdas durante o processamento. Quando excessivamente comprido, acarreta menor compacidade da cabeça e dificulta o beneficiamento, afetando a qualidade final do produto (Yuri et al., 2002). Na prática, caules de até $6,0 \mathrm{~cm}$ seriam mais adequados, sendo aceitáveis até $9,0 \mathrm{~cm}$; Acima deste valor não seria indicado para processamento industrial (Resende, 2004). Neste contexto, os valores de comprimento de caule, independente de épocas e doses de zinco ficaram abaixo de $6,0 \mathrm{~cm}$, estando dentro da faixa considerada adequada, não afetando a qualidade do produto final.

A circunferência da cabeça comercial foi influenciada significativamente tanto pela época de plantio (Tabela 1) quanto pelas doses de zinco (Figura 2). O plantio de inverno apresentou maior circunferência $(44,1 \mathrm{~cm})$ e menor valor foi observado para o cultivo de outono, quanto a circunferência da cabeça comercial atingiu $39,2 \mathrm{~cm}$. Yuri et al. (2004a) obtiveram variações no plantio de outono entre 39,2 e 49,2 cm, enquanto em condições de inverno, verificaram-se oscilações entre 35,6 e 49,2 cm (Yuri et al., 2004b). O efeito do zinco sobre o crescimento da alface é relatado por Zinc (1966), que obteve maior número de folhas e massa fresca da cabeça comercial. Fontes et al. (1982) observaram decréscimo de $17,4 \%$ no tamanho médio da cabeça de alface em estudo conduzido por dois anos. Salientaram a grande importância do zinco no desenvolvimento e produção da alface. A circunferência da cabeça está diretamente relacionada com a massa fresca da parte comercial, importante para o produtor, pois a remuneração, neste caso, ocorre de acordo com a massa fresca da cabeça da alface. Quanto maior a cabeça, normalmente maior é a massa fresca da planta. Esta é, também, uma característica importante para a indústria, pois afeta sobremaneira o rendimento no beneficiamento, no qual cabeças muito pequenas, diminuem o rendimento dos operadores.

No que se refere às doses, a circunferência da cabeça, ajustou-se a um modelo quadrático $(\mathrm{Y}=39,6360+$ $7,3005 X-8,2396 * X^{2} R^{2}=0,93$ ), sendo que a dose $0,44 \mathrm{~kg} / \mathrm{ha}$ de zinco proporcionou maior circunferência. Yuri et al. (2003) obtiveram maior circunferência da cabeça comercial com a dose de 0,52 $\mathrm{kg} / \mathrm{ha}$ de zinco em condições de inverno, assim como Fontes et al. (1982), concluíram ser o zinco de grande importância para o desenvolvimento e produção da alface. Maior circunferência da cabeça em função da aplicação de zinco está diretamente relacionada ao seu comportamento no metabolismo da planta, como já indicado anteriormente (Faquin, 1997; Grewal et al., 1997).

Em função dos resultados obtidos no presente trabalho, pode-se concluir que o cultivo da alface tipo americana, cv. Raider, é viável nas duas épocas de cultivo testadas, sendo o plantio sob condições de clima mais ameno (inverno) o mais adequado para a cultura. Recomenda-se a dose de $0,49 \mathrm{~kg} / \mathrm{ha}$ de zinco para maximizar a produtividade comercial.

\section{REFERÊNCIAS}

ABREU CA; FERREIRA ME; BORKERT CM. 2001. Disponibilidade e avaliação de elementos catiônicos: zinco e cobre. In: FERREIRA ME; CRUZ MCP; Van RAIJ B; ABREU CA (eds.) Micronutrientes tóxicos na agricultura. Jaboticabal: CNPq/ FAPESP/ POTAFOS, 600p.

ALVARENGA MAR. 1999. Crescimento, teor e acúmulo de nutrientes em alface americana (Lactuca sativa L.) sob doses de nitrogênio aplicadas no solo e de níveis de cálcio aplicados via foliar. Lavras: UFLA, 117p. (Tese doutorado).

BEBÉ FV; MATSUMOTO AS; FONTES PCR; MOREIRA MA; PIMENTEL CAS; RIBEIRO MS; CRUZ DS; FERRAZ SCN. 2004. Crescimento e produtividade de alface influenciados pela aplicação de fósforo no solo e de zinco via foliar. In: CONGRESSO BRASILEIRO DE OLERICULTURA, 44. Resumos.... Campo Grande: SOB (CD-ROM).

BUENO CR. 1998. Efeito da adubação nitrogenada em cobertura via fertirrigação por gotejamento para a cultura da alface tipo americana em ambiente protegido. Lavras: UFLA, 54 p. (Tese mestrado).
CASTELlANE PD; ARAUJO JAC. 1995. Cultivo sem solo: hidroponia. Jaboticabal: FUNEP, 43p.

CÁSSERES E. 1980. Producción de hortalizas. São José-Costa Rica: Instituto Interamericano de Ciências Agrícolas, 387p.

CHESWORTH W. 1991. Geochemistry of micronutrients. In: MORTVEDT JJ. Micronutrients in Agriculture. 2 ed. Madison: Soil Science Society American, p. 1-30.

CONTI JH. 1994. Caracterização de cultivares de alface (Lactuca satival L.) adaptadas aos cultivos de inverno e verão. Piracicaba: ESALQ, 117p. (Tese mestrado).

EMBRAPA - EMPRESA BRASILEIRA DE PESQUISA AGROPECUÁRIA. 1999. Sistema Brasileiro de Classificação de Solos. Brasília: Embrapa Produção de Informações (SPI), 412p.

FAQUIN V. 1997. Nutrição mineral de plantas. Lavras: UFLA-FAEPE. 227p.

FILGUEIRA FAR. 2000. Novo Manual de Olericultura: Agrotecnologia moderna na produção e comercialização de hortaliças. Viçosa: UFV. 402p.

FONTES RR; LIMA JA; TORRES AC; CARRIJO OA. 1982. Efeito da aplicação de $\mathrm{Mg}, \mathrm{B}, \mathrm{Zn}$ e Mo na produção de alface. Pesquisa Agropecuária Brasileira 17: 171175.

GREWAL HS; ZHONGGU L; GRANHAN RD. 1997. Influence of subsoil zinc on dry matter production, seed yield and distribution of zinc in oilseed rape genotypes differing in zinc efficiency. Plant and Soil 192: 181-189.

INSTITUTO BRASILEIRO DE GEOGRAFIA E ESTATÍSTICA-IBGE. 2004. Organização do território - vilas e cidades. Disponível em: <http://www.Ibge.gov.br>. Acessado em 19 agosto de 2004.

IORIO AF; GORGOSCHIDE L; RENDINA A; BARROS MJ. 1996. Effect of phosphorus, copper, and zinc addition on the phosphorus/ copper and phosphorus/zinc interaction in lettuce. Journal of Plant Nutrition 19: 481-491.

LINDQUIVIST K. 1960. On the origin of cultivated lettuce. Hereditas 46: 319-350.

MOREIRA MM; FONTES PCR; CAMARGOS MI. 2001. Interação entre zinco e fósforo em solução nutritiva influenciando o crescimento e a produtividade da alface. Pesquisa Agropecuária Brasileira 36: 903-909.

MOTA JH. 1999. Efeito do cloreto de potássio via fertirrigação na produção de alface americana em cultivo protegido. Lavras: UFLA. 46p. (Tese mestrado).

RESENDE GM. 2004. Características produtivas, qualidade pós-colheita e teor de nutrientes em alface americana (Lactuca sativa $\mathrm{L}$.) sob doses de nitrogênio e molibdênio, em cultivo de verão e de inverno. Lavras: UFLA. 139p. (Tese doutorado).

RESENDE GM; ALVARENGA MAR; YURI JE; MOTA JH; SOUZA RJ; RODRIGUES JÚNIOR JC. 2005a. Produtividade e qualidade pós-colheita da alface americana em função de doses de nitrogênio e molibdênio. Horticultura Brasileira 23: 976-981. 
RESENDE GM; YURI JE; MOTA JH; RODRIGUES JÚNIOR JC; SOUZA RJ; CARVALHO JG. 2005b. Resposta da alface tipo americana a doses e épocas de aplicação foliar de zinco. Caatinga 18: 66-72.

SANDERS DC. 1999. Lettuce production. Disponível em: <http//www.ces.ncsu.edu/ depts/hort/hil/hil-11.html>. Acessado em 10 outubro de 1999.

SANTOS RH; SILVAF; CASALI VWD; CONDE AR. 2001. Efeito residual da adubação com composto orgânico sobre o crescimento e produção de alface. Pesquisa Agropecuária Brasileira 36: 1395-1398.

WELCH RM; NORVELL WA. 1996. Growth and nutrient uptake of barley (Hordeum vulgare $\mathrm{L}$. cv. Herta): studies using an N-(2hydroxyethyl)ethylenedinitrilotriacetic acidbuffered nutrient solution technique. 1. Role of zinc in the uptake and root leakage of mineral nutrients. Plant Physiology 101: 627-631.
WHITAKER TW; RYDER JE. 1974. Lettuce production in the United States. Washington: USDA, 43p. (USDA. Washington Agriculture Handbook, 221).

YURI JE; SOUZA RJ; FREITAS SAC; RODRIGUES JÚNIOR JC; MOTA JH. 2002. Comportamento de cultivares de alface tipo americana em Boa Esperança. Horticultura Brasileira 20: 229-232.

YURI JE; RESENDE GM; MOTA JH; FREITAS SAC; RODRIGUES JUNIOR JC; SOUZA RJ; CARVALHO JG; OKADA AT. 2003. Adubação foliar com zinco para alface americana em cultivo de inverno. In: CONGRESSO BRASILEIRO DE OLERICULTURA, 43. Resumos... Recife: SOB (CD-ROM).
YURI JE; MOTA JH; RESENDE GM; SOUZA RJ; RODRIGUES JUNIOR JC. 2004a. Desempenho de cultivares de alface tipo americana em cultivo de outono no Sul de Minas Gerais. Ciência e Agrotecnologia 28: 284-288.

YURI JE; RESENDE GM; MOTA JH; SOUZA RJ; RODRIGUES JUNIOR JC. 2004 b. Comportamento de cultivares e linhagens de alface americana Santana da Vargem (MG), nas condições de inverno. Horticultura Brasileira 22: 322-325.

YURI JE; RESENDE GM; SOUZA RJ; MOTA JH. 2005. Comportamento de cultivares de alface americana em Santo Antônio do Amparo. Horticultura Brasileira 23: 870-874.

ZINC FW. 1966. The response of head lettuce to soil application of zinc. Proceedings Society Horticultural Science 69: 406-414. 